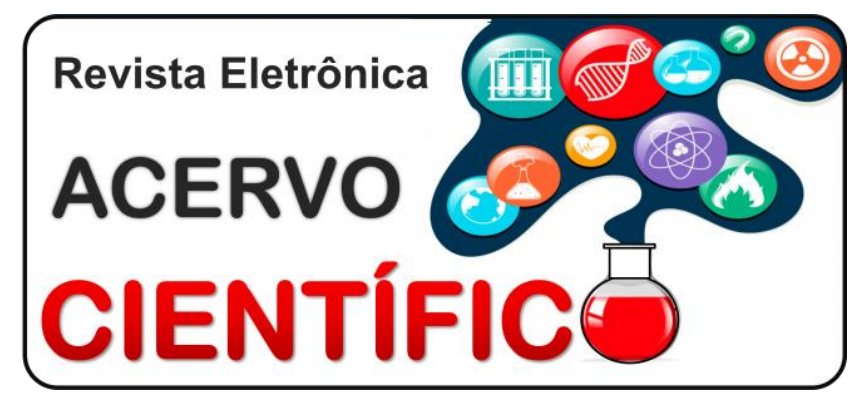

RELATO DE EXPERIÊNCIA

Recebido em: 7/2019

Aceito em: 8/2019

Publicado em: 10/2019

\title{
A importância do brincar durante a internação hospitalar: um relato de experiência
}

\author{
The importance of play during hospitalization: a report of experience
}

La importancia de jugar durante la hospitalización: un informe de experiencia

Adilson Mendes de Figueiredo Júnior ${ }^{1 *}$, Deborah Pereira Reis ${ }^{1}$, Keila Nascimento Lima1.

\begin{abstract}
Resumo: Esse artigo buscou relatar a experiência de alunos do $7^{\circ}$ semestre do curso de graduação em enfermagem sobre a importância do brincar para crianças e seus familiares durante a internação hospitalar, através de um estudo descritivo, tipo relato de experiência, elaborado no contexto do estágio curricular obrigatório da disciplina de Enfermagem Pediátrica, durante o sétimo semestre do curso de Graduação em Enfermagem. A hospitalização é um momento difícil na vida da criança pode se configurar como uma experiência traumática, pois proporciona, na mesma, insatisfações momentâneas ou prejuízos que vão além da internação. Portanto, são viáveis os projetos que são apresentados às crianças e vem trazendo benefícios saudáveis aos estilos de vida dos mesmos dentro dos hospitais. Fica explícito que o brincar faz toda diferença na recuperação do paciente pediátrico em relação a sua melhora do quadro clinico, podendo evitar estresse, depressão ou isolamento daquela criança.
\end{abstract}

Palavras-chave: Enfermagem, Pediatria, Lúdico.

\begin{abstract}
This article aimed to report the experience of students of the 7th semester of the undergraduate nursing course about the importance of playing for children and their families during hospitalization, through a descriptive study, like experience report, elaborated in the context of the internship. Compulsory curriculum of the discipline of Pediatric Nursing, during the seventh semester of the Undergraduate Nursing course. Hospitalization is a difficult time in the child's life and can be configured as a traumatic experience, as it provides momentary dissatisfaction or damage that goes beyond hospitalization. Therefore, projects that are presented to children are viable and have brought healthy benefits to their lifestyles within hospitals. It is explicit that playing makes all the difference in the recovery of the pediatric patient in relation to their improvement of the clinical condition, and can avoid stress, depression or isolation of that child.
\end{abstract}

Keywords: Nursing, Pediatrics, Ludic.

Resumen: Este artículo tuvo como objetivo informar la experiencia de los estudiantes del séptimo semestre del curso de enfermería de pregrado sobre la importancia de jugar para los niños y sus familias durante la hospitalización, a través de un estudio descriptivo, como el informe de experiencia, elaborado en el contexto de la pasantía. Currículo obligatorio de la disciplina de Enfermería Pediátrica, durante el séptimo semestre del curso de Pregrado en Enfermería. La hospitalización es un momento difícil en la vida del niño y puede configurarse como una experiencia traumática, ya que proporciona una insatisfacción momentánea o un daño que va más allá de la hospitalización. Por lo tanto, los proyectos que se presentan a los niños son viables y han traído beneficios saludables a sus estilos de vida dentro de los hospitales. Es explícito que jugar hace toda la diferencia en la recuperación del paciente pediátrico en relación con su mejoría de la condición clínica, y puede evitar el estrés, la depresión o el aislamiento de ese niño.

Palabras-clave: Enfermería, Pediatría, Juguetón.

1Escola Superior da Amazônia (ESAMAZ), Belém-Pará. *E-mail: adilsonmdfi@hotmail.com 


\section{INTRODUÇÃO}

Sabe-se da importância da participação das crianças nas brincadeiras. Para pré-escolares, as que são simples e imitativas favorecem o aprendizado e possibilitam a diversão, iniciando com jogos convencionais brincadeiras ritualistas e progredindo para jogo atribuído de competições, isso estimula e desenvolve competências psicomotoras na criança. Portanto, são viáveis os projetos que são apresentados às crianças e vem trazendo benefícios saudáveis aos estilos de vida dos mesmos dentro dos hospitais (TOLOCKA RE, et al. 2019).

O processo de adoecimento infantil afeta toda a família, gerando momentos de dificuldades e desespero; o apoio da equipe de saúde e a efetivação de manobras que possam amenizar esse sofrimento são essenciais para o processo de "cuidar". É no momento do adoecimento e internação que muitas crianças e adolescentes vivenciam experiências traumáticas e de sofrimento, assim seu cotidiano no ambiente hospitalar é marcado por ansiedade e medo, principalmente, pelo afastamento do ambiente escolar, dos amigos e dos próprios familiares; os sentimentos são de diferentes ordens, como medo, raiva, insegurança e incertezas (MARQUES EP, et al. 2016).

O cenário regional ainda é muito sugestivo para o adoecimento infantil, e muitos profissionais da saúde percebem que o "cuidar" supera a tradicional visão biomédica, sendo o contexto holístico o mais completo para a avaliação dos pacientes internados. O "brincar" torna-se a continuidade do cotidiano infantil mesmo em uma área de internação, e ajuda na evolução biológica e psicológica de crianças e familiares. Para os profissionais de saúde, a ludicidade não interfere apenas nos sujeitos do cuidado, mas estimula o desenvolvimento profissional da equipe de saúde e até mesmo o bem-estar físico, laboral e mental dos mesmos (SILVA MB e ALMEIDA AO, 2016).

Ocorre uma ruptura com o cotidiano, onde essas crianças que saem de seu ambiente de conforto e sua rotina (ir à escola, brincar, estar com familiares e amigos) e vão para um ambiente desconhecido, que gera um choque de realidade e que provoca sentimentos expressos no choro, agressividade, dependência, acarretando em ansiedade, depressão e angústia (MARQUES EP, et al. 2016).

As atividades lúdicas são manobras importantes que os profissionais da saúde utilizam para a minimização do sofrimento e das manifestações patológicas, principalmente, no tratamento do câncer infantil, ou seja, a ludicidade é um potencializador no processo de enfrentamento e adaptação do ambiente hospitalar transformando, muitas vezes, momentos de medo e aflição em vivências menos traumáticas (MARQUES EP, et al. 2016).

O Ministério da Saúde afirma que o tratamento medicamentoso não é a terapia mais importante para o combate a doenças, mas deve-se levar em consideração os aspectos biopsicossociais para efetivação do cuidado integral e familiar (SILVA MB e ALMEIDA AO, 2016).

Diante disso, o atual estudo teve como objetivo geral relatar a experiência de alunos do $7^{\circ}$ semestre do curso de graduação em Enfermagem sobre a importância do brincar para crianças e seus familiares durante a internação hospitalar.

\section{RELATO DE EXPERIÊNCIA}

Foi realizado no período de 16 de abril até 15 de maio do ano de 2018, em uma maternidade de referência em saúde da mulher e da criança, localizada no município de Belém/PA.

Utilizamos como metodologia a observação da rotina da assistência da equipe multiprofissional quanto à utilização da brincadeira no processo de hospitalização, e ainda foram realizadas conversas informais com as crianças internadas, seus acompanhantes e profissionais da saúde sobre a vivência do lúdico no contato hospitalar. Durante a rotina as crianças eram estimuladas com jogos de quebra cabeças e de memória para incentivo de desenvolvimento cognitivo, as brincadeiras eram recebidas com boa receptividade pelas crianças que participavam ativamente das dinâmicas. 
Cinco crianças que se encontravam hospitalizadas no setor pediátrico em questão foram observadas, onde elas tinham idades diferentes entre um ano e seis meses até 11 anos de idade. A pouca idade nos leva a perceber que essas crianças podem não estar preparadas emocionalmente o bastante para lidar com a experiência total de uma internação, sendo a hospitalização um evento traumático com procedimentos invasivos como sondagem, acessos venosos, cirurgias, dentre outros.

No setor de pediatria do hospital, lócus da pesquisa, o terapeuta ocupacional e a assistente social são responsáveis pelas brincadeiras, as quais são realizadas no próprio leito da criança, sendo conduzidas pelos profissionais em dois dias da semana, na terça-feira pela manhã e quinta-feira pela tarde, quando a equipe leva ideias novas e estratégias diversas para o aprendizado e a diversão, através do uso de brinquedos, livros de desenho, lápis de cor, massinha, músicas alegres, brinquedos coloridos.

Para as crianças com pouca movimentação, é realizada a estimulação destes através de brinquedos com emissão de sons. Além disso, a equipe multidisciplinar ensina os pais a prestar a assistência aos seus filhos diariamente estimulando o brincar no leito e afirmam que os pais são os principais educadores e construtores de confiança, amor, e dedicação e estimulam o aprendizado e alegria todos os dias com seu jeito de brincar.

Muitos enfermeiros relatavam a progressão clínica das crianças e percebiam que o envolvimento dos familiares com a equipe multiprofissional aumentavam as possibilidades de progressão no tratamento e de aceitamento da doença. A aceitabilidade dos pais e responsáveis era ampla e demonstrava a credibilidade dos meios utilizados.

No familiar com câncer infantil a vivência dos longos períodos de hospitalização causa alterações da rotina e da dinâmica familiar, interferido diretamente nas relações interpessoais. As internações frequentes, a terapêutica agressiva e a interrupção das atividades cotidianas acabam comprometendo a estabilidade do indivíduo e do familiar, pois muitos vivenciam sentimentos de medo e de dor.

\section{DISCUSSÃO}

A hospitalização é um momento difícil na vida da criança pode se configurar como uma experiência traumática, pois proporciona, na mesma, insatisfações momentâneas ou prejuízos que vão além da internação, bem como as afastam de sua vida cotidiana e do ambiente familiar colocando-se em um mundo diferente, constituído de equipamentos, pessoas desconhecidas, limitações de movimento, cheiros, procedimentos e dores (SPOSITO AMP, et al. 2018).

A ludicidade é tão importante para a saúde mental quanto física e é um aspecto que merece atenção no conceito de saúde dos familiares e dos profissionais que necessitam de atenção, pois também adoecem juntamente com as crianças no processo de enfrentamento da doença (SILVA LF e CABRAL IE, 2015).

Ratificando a importância do brincar para as crianças, pudemos ouvir vários relatos destas que diziam, dentre outras coisas, que "o horário de brincar é o melhor, pois, lembra o ambiente familiar e escolar no momento da atividade física".

$\mathrm{Na}$ vida, a fase da infância é representada pelas diversas fases do brincar e através dessa prática que muitos desenvolvem suas experiências de vida, as descobertas e a realização da construção da personalidade, dessa maneira, ressalta-se a importância da utilização de recursos que possam desenvolver o crescimento e o potencial mental de cada indivíduo a fim de reduzir consequências negativas que a doença possa causar (PAIXÃO AB, et al. 2016).

Dessa forma, observamos que a equipe de profissionais usa como estratégia dois tipos de brinquedos, 0 normativo e o terapêutico. O brinquedo normativo é aquele realizado de forma empírica por cada criança, sendo necessário para a manutenção da rotina da criança e maior conforto na estadia no ambiente hospitalar. Já o brinquedo terapêutico é aquele com objetivo bem definido e que necessita de um profissional para direcionar a criança (SPOSITO AMP, et al. 2018). 
O tratamento terapêutico pode amenizar o desconforto causado pelas normas e rotinas do hospital, minimizar a ansiedade e ajudar a entender os procedimentos que precisam ser realizados durante a internação, sendo necessário haver material lúdico específico para que possa aplicá-lo de maneira mais efetiva favorecendo a demonstração e a assimilação dos procedimentos (MARGRID ANATB, 2010).

Ao passar a visita de rotina, notamos que o sofrimento e cansaço das mães eram visíveis e estas nos relataram que a área de recreação deveria acontecer todos os dias e não só duas vezes na semana como acontece no hospital, sendo necessário um profissional disponível para acompanhar essas crianças todos os dias e um espaço específico na ala de pediatria.

A ludoterapia é uma intervenção psicoterapêutica com resultados extremamente positivos para criança e o familiar, pois através da brincadeira é possível a expressão das emoções, das vivências e experiências. As brincadeiras fazem parte da construção social da infância e do desenvolvimento mental e cognitivo das crianças, independente das limitações existentes, a brincadeira deve ser presente na vida de todos (PAIXÃO AB, et al. 2016).

A ausência de maiores espaços para a oportunidade do desenvolvimento de brincadeiras e interação é percebida e referida pelos próprios pais e acompanhantes das crianças. A deficiência de brinquedos disponíveis faz com que os pais levem os próprios brinquedos da criança de casa para o hospital, tendo em vista reconhecerem a importância do brincar para a criança.

O brincar nesse hospital ainda que o mesmo não tenha uma brinquedoteca representa para crianças a diminuição de sofrimento físico e psicológico e aumenta o vínculo com seus pais e com a equipe multiprofissional e propicia sorrisos e expressões de sentimentos.

A atividade lúdica na criança hospitalizada é essencial. Transfere e possibilita à criança momentos de alegria e desperta o imaginário tirando do seu mundo real cheio de dor, fraqueza, medo e desespero para momentos inesquecíveis.

O profissional responsável pelo cuidado deve atender a criança juntamente com a sua família a fim de encontrar estratégias para ter a melhor relação possível entre todos, dessa forma, aumentando a qualidade de vida durante o tratamento onde se valoriza todos os aspectos holísticos sendo o "brincar" uma ferramenta fundamental para o desenvolvimento individual, profissional e familiar (SILVA LF e CABRAL IE, 2015).

\section{CONSIDERAÇÕES FINAIS}

Levando-se em conta o que foi observado, fica explícito que o brincar é determinante na recuperação do paciente pediátrico em relação a sua melhora do quadro clínico, podendo evitar estresse, depressão ou isolamento daquela criança, devido à falta de recreação; é de suma importância manter a integridade do brincar e a interação de uma criança com outra criança sempre que possível, pois isso tornará menos traumático à estadia desse ser no âmbito hospitalar, é interessante também propiciar momentos de lazer, brincadeiras, fornecer brinquedos e também atividades que façam essa criança lembrar que é criança e que independente do seu estado ela pode brincar sim. Os profissionais são de grande valia nesse processo e é preciso sensibilizá-los que o olhar para aquele paciente deve ser de forma holística. Contudo, ficou nítido que o momento das atividades lúdicas é o mais aguardado por esses pacientes pediátricos e que faz toda a diferença em sua recuperação, esse momento de lazer e descontração deve ser levado em consideração como uma forma também de tratamento para a cura ou melhora da qualidade de vida daquele indivíduo.

\section{REFERÊNCIAS}

1. MARGRID ANATB. Expressões lúdicas no cuidado hospitalar sob a ótica de enfermeiras. Esc. Anna Nery. 2010; 14(3): 567-574.

2. MARQUES EP, et al. Lúdico no cuidado à criança e ao adolescente com câncer: perspectivas da equipe de enfermagem. Esc. Anna Nery. 2016; 20(3). 
3. OLIVEIRA VB. Apoio à família da criança hospitalizada via lúdico. Boletim Academia Paulista de Psicologia. 2013; 33(84): 103-117.

4. PAIXAO AB, et al. Importância das atividades lúdicas na terapia oncológica infantil. Cuidarte Enfermagem. 2016; 10(2): 209-216.

5. SILVA LF, CABRAL IE. O resgate do prazer de brincar da criança com câncer no espaço hospitalar. Revista Brasileira de Enfermagem. 2015; 68(3): 391-7.

6. SILVA MB, ALMEIDA, OA. Brincar e Aprender em Hospitais: enfrentamento da doença na infância. Revista Educativa - Revista de Educação, Goiânia. 2016; (19)1: 33-51.

7. SPOSITO AMP, et al. O melhor da hospitalização: contribuições do brincar para o enfrentamento da quimioterapia. av. enferm., Bogotá. 2018; 36(3): 328-337.

8. TOLOCKA RE, et al. Brincar e crianças com câncer: que relação é esta?. Licere. 2019; 22(1): 421-444. 